\title{
Parasite-Derived Proteins for the Treatment of Allergies and Autoimmune Diseases
}

\author{
Zhenyu Wu ${ }^{1,2,3+}$, Lifu Wang ${ }^{1,2,3+}$, Yanlai Tang ${ }^{4}$ and Xi Sun ${ }^{1,2,3 *}$ \\ 'Department of Parasitology, Zhongshan School of Medicine, Sun Yat-sen University, Guangzhou, China, ${ }^{2}$ Key Laboratory \\ of Tropical Disease Control (SYSU), Ministry of Education, Guangzhou, China, ${ }^{3}$ Provincial Engineering Technology Research \\ Center for Diseases-Vectors Control, Guangzhou, China, ${ }^{4}$ Department of Pediatrics, The First Affiliated Hospital, Sun \\ Yat-sen University, Guangzhou, China
}

\section{OPEN ACCESS}

Edited by:

Wei Hu,

Fudan University, China

Reviewed by:

Magilé De La Caridad Fonseca, Instituto de Medicina Tropical "Pedro Kouri", Cuba

George Grant,

University of Aberdeen,

United Kingdom

*Correspondence:

Xi Sun

sunxi2@mail.sysu.edu.cn

†These authors have contributed equally to this work and are co-first authors.

Specialty section:

This article was submitted to Infectious Diseases,

a section of the journal

Frontiers in Microbiology

Received: 10 June 2017 Accepted: 20 October 2017 Published: 07 November 2017

Citation:

Wu Z, Wang L, Tang $Y$ and Sun $X$

(2017) Parasite-Derived Proteins for the Treatment of Allergies and Autoimmune Diseases.

Front. Microbiol. 8:2164. doi: 10.3389/fmicb.2017.02164
The morbidity associated with atopic diseases and immune dysregulation disorders such as asthma, food allergies, multiple sclerosis, atopic dermatitis, type 1 diabetes mellitus, and inflammatory bowel disease has been increasing all around the world over the past few decades. Although the roles of non-biological environmental factors and genetic factors in the etiopathology have been particularly emphasized, they do not fully explain the increase; for example, genetic factors in a population change very gradually. Epidemiological investigation has revealed that the increase also parallels a decrease in infectious diseases, especially parasitic infections. Thus, the reduced prevalence of parasitic infections may be another important reason for immune dysregulation. Parasites have co-evolved with the human immune system for a long time. Some parasite-derived immune-evasion molecules have been verified to reduce the incidence and harmfulness of atopic diseases in humans by modulating the immune response. More importantly, some parasite-derived products have been shown to inhibit the progression of inflammatory diseases and consequently alleviate their symptoms. Thus, parasites, and especially their products, may have potential applications in the treatment of autoimmune diseases. In this review, the potential of parasite-derived products and their analogs for use in the treatment of atopic diseases and immune dysregulation is summarized.

Keywords: parasite, product, hygiene hypothesis, autoimmune disease, allergy

\section{INTRODUCTION}

Parasites, which have co-evolved with mammals, including humans, over a long period of time, can use various strategies to survive, such as secreting immune-evasion molecules to modulate the host immune system. However, consequently, parasites play a dual role in human health (Ditgen et al., 2014; Maizels and McSorley, 2016). On the one hand, parasites threaten human health by causing malnutrition, mechanical damage, and toxic effects. On the other hand, parasites induce potent immunomodulatory effects and can act as potential therapeutics for a variety of inflammatory diseases including asthma, rhinitis, intestinal inflammation disease, type 1 diabetes (T1D), and several other immune dysregulation disorders.

Conventional wisdom suggests that there are three consequences of parasitic infection: (1) The damage caused by the host response exceeds the ability of the parasites to adapt, the parasites are 
all cleared, and the host can resist or partially resist re-infection; (2) the host can only remove some of the parasites, the infection becomes chronic so that the host is a parasite carrier, and the host has partial resistance against re-infection (most host-parasite interactions belong in this category); (3) the parasites cause many pathogenic reactions or high levels of pathogenicity and the host cannot effectively remove the parasites, leading to significant pathological changes and clinical symptoms.

Parasitosis is a major public health problem worldwide and seriously threatens human health and life, especially in underdeveloped areas (Cooke, 2009; de Ruiter et al., 2017). According to the World Health Organization, more than a billion people around the world suffer from parasitic diseases. Thus, parasites, as enemies of human health, cause serious damage to human health. The activities of parasites, including invasion, migration, settlement, development and breeding, lead to damage to the host cells, tissues and organs, and even to the whole system.

However, with the decrease in parasitic infections, the incidence and harmfulness of atopic diseases (including asthma, allergic rhinitis, food allergies, anaphylaxis, and atopic dermatitis) and immune-mediated disorders (including T1D and inflammatory bowel disease) have been increasing remarkably all over the world, especially in developed countries (Heylen et al., 2014b; Stiemsma et al., 2015). Greenwood (1969) first observed the negative correlation between parasites and immune dysregulation. The low incidence of rheumatoid arthritis in Western Nigeria may be related to exposure to the malaria parasite (Greenwood, 1969; Garg et al., 2014). Later, Greenwood et al. (1970) observed that infection by Plasmodium berghei can suppress spontaneous autoimmune disease in mice. The "hygiene hypothesis" was then proposed by Strachan (1989). According to this hypothesis, exposure to infectious diseases in childhood can prevent adults from developing atopic diseases. As a result, the increase in atopic diseases can be attributed to the control of infectious agents such as parasites, especially helminths (Strachan, 1989).

Helminth infections mainly occur in developing countries and they are rare in industrialized counties. Helminths can be divided into two phyla: Platyhelminthes (flat worms), including both trematodes and cestodes, and Nemathelminths, including nematodes. They are mostly found in the gastrointestinal tract. Helminths have co-evolved with their hosts, such as humans, for millions of years. They can parasitize their hosts for a long time. For example, Wuchereria bancrofti can live in the human body for more than 10 years and Trichinella spiralis for up to 30 years (Harnett and Harnett, 2010). The goal of the parasitism is not to kill the host but to survive for as long as possible by maintaining a state of balance with the host. Thus, parasites need to employ various mechanisms to modulate the host immune system in order to prevent activation that may lead to their elimination and, at the same time, not cause serious immunosuppression that leads to the death of the host induced by a subsequent infectious disease. This mechanism of immunomodulation, avoiding excessive activation of the host immune system, can also be used by the host to protect against certain inflammatory disorders.

According to the hygiene hypothesis, humans have established an immunological balance between the TH1/TH17 and TH2 responses, of which the $\mathrm{TH} 1 / \mathrm{TH} 17$ response is related to bacterial infections and autoimmunity and the $\mathrm{TH} 2$ response is related to parasite infections and allergies. Parasite infection stimulates a strong TH2 response but inhibits the TH1 response, resulting in the inhibition of autoimmunity. Based on this finding, it seems that parasites can hinder the progression of allergic disease. In fact, parasite infection cannot induce the formation of allergyrelated $\operatorname{IgE}$ but it can induce the formation of polyclonal $\operatorname{IgE}$, which is not capable of inducing allergic diseases (Erb, 2009). In addition, parasites can induce immune tolerance by secreting anti-inflammatory products to modulate the immune response (Yazdanbakhsh et al., 2002; Li et al., 2017). Furthermore, parasites can also amplify T-regulatory (Treg) and B-regulatory (B-reg) cells and type- 2 macrophages, hamper dendritic cells (DCs) toward the tolerogenic phenotype, downregulate type-2 innate lymphoid cells (ILC2), and further modulate the gut microbiota (Rook, 2012; Versini et al., 2015).

Many attempts have been made to administer parasites, especially helminths, to treat allergies and autoimmunity. Different species of helminths and administration approaches have been evaluated in experimental models and clinical studies (Table 1). In a murine model of experimental autoimmune encephalomyelitis (EAE), the injection of schistosome eggs relieved the symptoms and prevented relapse (Zheng et al., 2008). However, the direct application of parasites is less likely to be acceptable to patients as they may develop parasitic diseases. Considering that parasite-derived antigens may have similar functions to the parasite itself, some researchers have attempted to use parasite-derived antigens instead of the parasite itself to obtain desirable outcomes. van Die and Cummings (2010) discovered that parasitic proteins such as surface and secretory antigens can inhibit the immune response, so they represent potential treatments for atopic diseases.

Thus, in this review, we will summarize various parasitederived products and their mechanisms to protect against atopic and autoimmune diseases.

\section{ES-62}

Acanthocheilonema viteae has been reported to live for a long time in humans, and ES-62 is a major excretory-secretory (ES) product of $A$. viteae that has been shown to modulate the human immune response in an early time (Stepek et al., 2002; Houston and Harnett, 2004). ES-62 is a glycoprotein with a phosphorylcholine (PC) attached to the uncharacterized $N$-glycan, and PC plays a central role in immune regulation (Agrawal et al., 2003).

ES-62 can promote a $\mathrm{TH} 2$ response via an interaction with Toll-like receptor 4 (TLR4). Normal TLR4 can recognize pathogen-associated molecular patterns (PAMPs) such as lipopolysaccharide (LPS) to recruit myeloid differentiation primary-response protein 88 (MyD88), which induces the 
TABLE 1 | Experimental studies and human trials of parasite-derived therapies for important autoimmune diseases.

\begin{tabular}{|c|c|c|c|c|}
\hline Autoimmune disease & Parasite & Effect & Useful component & Reference \\
\hline \multirow[t]{12}{*}{$\begin{array}{l}\text { Inflammatory bowel } \\
\text { disease (IBD) }\end{array}$} & $\begin{array}{l}\text { Schistosoma } \\
\text { mansoni }\end{array}$ & $\begin{array}{l}\text { S. mansoni cercaria infection attenuates } \\
\text { DSS-induced colitis in mice. Immunization with } \\
\text { P28GST, a unique recombinant schistosome } \\
\text { enzyme, ameliorates intestinal inflammation by } \\
\text { eosinophil-dependent modulation of harmful type } 1 \\
\text { responses, representing a new immunoregulatory } \\
\text { strategy against IBD (Driss et al., 2016). }\end{array}$ & $\begin{array}{l}\text { Soluble egg antigen (SEA), } \\
\text { soluble worm antigen (SWA), } \\
\text { glutathione S-transferase } \\
\text { P28GST, Sj16 }\end{array}$ & $\begin{array}{l}\text { Ruyssers et al., 2009; } \\
\text { Bodammer et al., 2011; } \\
\text { Heylen et al., 2014a; } \\
\text { Hasby et al., 2015; } \\
\text { Driss et al., } 2016\end{array}$ \\
\hline & $\begin{array}{l}\text { Schistosoma } \\
\text { japonicum }\end{array}$ & $\begin{array}{l}\text { S. japonicum ova pre-treatment contributes to the } \\
\text { relief of colitis and decreases mortality in a } \\
\text { TNBS-induced colitis model, modulating the activity } \\
\text { of CD4+CD25+Treg cells. }\end{array}$ & Cystatin & $\begin{array}{l}\text { Xia et al., 2011; } \\
\text { Wang et al., } 2016\end{array}$ \\
\hline & $\begin{array}{l}\text { Ancylostoma } \\
\text { caninum }\end{array}$ & $\begin{array}{l}\text { Ameliorates TNBS-induced colitis in mice, } \\
\text { decreases production of pro-inflammatory } \\
\text { cytokines (IFN- } \gamma \text { and IL-17), and increases } \\
\text { production of regulatory cytokines (IL-10 and } \\
\text { TGF- } \beta \text { ) in colon tissue. }\end{array}$ & Soluble antigen & Ruyssers et al., 2009 \\
\hline & $\begin{array}{l}\text { Hymenolepis } \\
\text { diminuta }\end{array}$ & $\begin{array}{l}\text { Colitis suppressed by adoptive transfer of } \\
\text { antigen-treated dendritic cells. }\end{array}$ & Adult worm extract & $\begin{array}{l}\text { Reyes et al., 2015, } \\
2016 a ; \text { Matisz et al., } \\
2017\end{array}$ \\
\hline & Anisakis & $\begin{array}{l}\text { Anisakis excretory-secretory (ES) compounds have } \\
\text { a protective effect on intestinal immunopathology. }\end{array}$ & $\begin{array}{l}\text { ES products isolated from } \\
\text { Anisakis larvae }\end{array}$ & Haarder et al., 2017 \\
\hline & $\begin{array}{l}\text { Ascaris } \\
\text { lumbricoides }\end{array}$ & $\begin{array}{l}\text { Reduces inflammation in a mouse model of } \\
\text { DSS-induced colitis, probably by increasing the } \\
\text { expression of anti-inflammatory cytokines (IL-10 } \\
\text { and TGF- } \beta \text { ) and reducing pro-inflammatory ones } \\
\text { (IL-6 and TNF- } \alpha \text { ). }\end{array}$ & Recombinant cystatin & Coronado et al., 2017 \\
\hline & $\begin{array}{l}\text { Heligmosomoides } \\
\text { polygyrus }\end{array}$ & $\begin{array}{l}\text { Alteration of the gut microbiota is a significant } \\
\text { contributor to the } H \text {. polygyrus-induced } \\
\text { exacerbation of } C \text {. rodentium colitis. }\end{array}$ & & Su et al., 2017 \\
\hline & Trichuris suis & $\begin{array}{l}\text { Clinical trials using } T \text {. suis for treatment of active } \\
\text { Crohn's disease and ulcerative colitis showed that } \\
\text { most of the patients experienced clinical } \\
\text { improvement and no adverse effects. }\end{array}$ & Ova & $\begin{array}{l}\text { Summers et al., 2003, } \\
\text { 2005a,b; Elliott and } \\
\text { Weinstock, 2017; } \\
\text { Su et al., 2017; }\end{array}$ \\
\hline & $\begin{array}{l}\text { Necator } \\
\text { americanus }\end{array}$ & $\begin{array}{l}\text { Clinical trials showed that } N \text {. americanus L3 may } \\
\text { have a therapeutic effect on Crohn's disease, with } \\
\text { improved CDAl in } 5 / 9 \text { patients at } 20 \text { weeks and } 3 / 5 \\
\text { patients at } 45 \text { weeks, and mild adverse events. }\end{array}$ & & $\begin{array}{l}\text { Elliott and Weinstock, } \\
2017\end{array}$ \\
\hline & Clonorchis sinensis & $\begin{array}{l}\text { Reduces DSS-induced colitis by induction of IL-10 } \\
\text { production by macrophages. }\end{array}$ & $\begin{array}{l}\text { Recombinant type- } 1 \text { cystatin } \\
\text { (Csstefin-1) }\end{array}$ & Jang et al., 2011 \\
\hline & Brugia malayi & $\begin{array}{l}\text { Reduces T-cell-mediated colitis by reducing IFNr } \\
\text { and IL-17 in the spleen, mesenteric lymph nodes, } \\
\text { and lamina propria, and increasing IL-4 and IL-10. }\end{array}$ & $\begin{array}{l}\text { Recombinant asparaginyl-tRNA } \\
\text { synthetase (AsnRS) }\end{array}$ & Kron et al., 2013 \\
\hline & $\begin{array}{l}\text { Echinococcus } \\
\text { granulosus }\end{array}$ & $\begin{array}{l}\text { Attenuates DSS-induced colitis by reducing iNOS } \\
\text { expression in the colon but not in the plasma }\end{array}$ & Laminated layer crude extract & Soufli et al., 2015 \\
\hline \multirow[t]{2}{*}{ Rheumatoid arthritis } & $\begin{array}{l}\text { Schistosoma } \\
\text { mansoni }\end{array}$ & $\begin{array}{l}\text { Protective effects on the clinical and } \\
\text { immunopathological features of rheumatoid arthritis } \\
\text { by reducing serum IL-17 and increasing IFN-r and } \\
\text { IL-10. Reduces collagen-induced arthritis by } \\
\text { downregulation of the Th1 (IFN-r) response and } \\
\text { pro-inflammatory cytokines (TNF- } \alpha \text { and IL-17A), } \\
\text { and upregulation of the Th2 (IL-4) response and an } \\
\text { anti-inflammatory cytokine (IL-10). }\end{array}$ & $\begin{array}{l}\text { Autoclaved S. mansoni antigen } \\
\text { (ASMA) }\end{array}$ & Eissa et al., 2016 \\
\hline & $\begin{array}{l}\text { Schistosoma } \\
\text { japonicum }\end{array}$ & $\begin{array}{l}\text { Attenuates murine collagen-induced arthritis by } \\
\text { augmenting IL-4, IL-10, and collagen-specific IgG1, } \\
\text { distinctly reducing IFN-r and collagen-specific } \\
\text { IgG2a, and decreasing IL-6, IL-17, TNF- } \alpha \text {, and } \\
\text { RANKL. Reduces severity of complete Freund's } \\
\text { adjuvant-induced arthritis in a rat model by } \\
\text { increasing production of IL-10 and IL-4 and } \\
\text { decreasing production of IL-12p70 and IFN-r. }\end{array}$ & $\begin{array}{l}\text { Recombinant SjCystatin and } \\
\text { Sj16 }\end{array}$ & $\begin{array}{l}\text { Sun et al., 2010; Song } \\
\text { et al., 2011; Liu et al., } \\
2016\end{array}$ \\
\hline
\end{tabular}


TABLE 1 | Continued

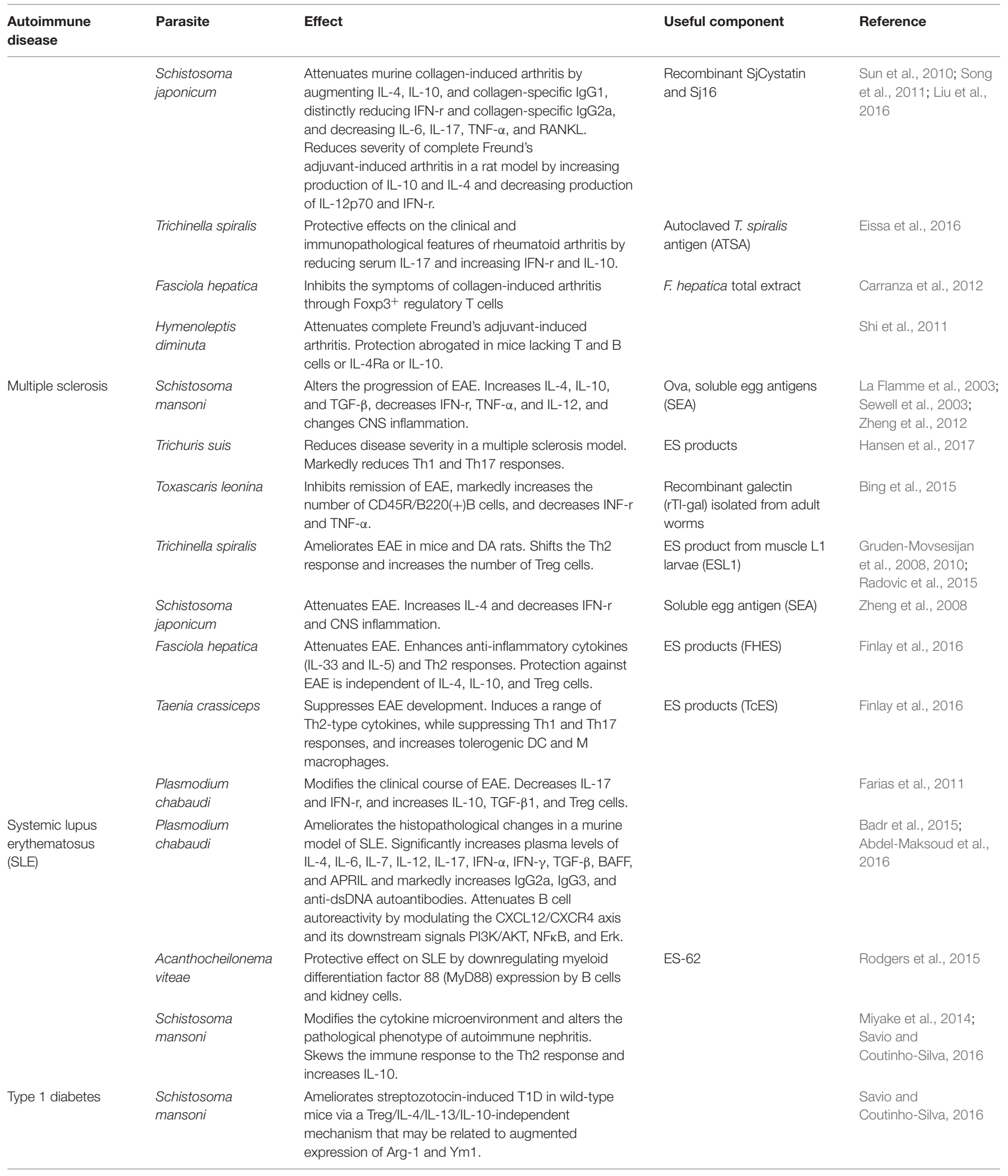


TABLE 1 | Continued

\begin{tabular}{|c|c|c|c|c|}
\hline $\begin{array}{l}\text { Autoimmune } \\
\text { disease }\end{array}$ & Parasite & Effect & Useful component & Reference \\
\hline & Brugia malayi & $\begin{array}{l}\text { rBMALT-2 has effective immunomodulatory and } \\
\text { anti-diabetic effects by skewing the immune } \\
\text { response to the Th2 response. }\end{array}$ & $\begin{array}{l}\text { Filarial abundant larval } \\
\text { transcript } 2 \text { (ALT-2) }\end{array}$ & Reddy et al., 2017 \\
\hline & Fasciola hepatica & $\begin{array}{l}\text { Ameliorates SLE and modulates macrophage } \\
\text { function. }\end{array}$ & FhHDM-1 & Reddy et al., 2017 \\
\hline & Trichinella spiralis & $\begin{array}{l}\text { Prevents diabetes in NOD mice by disrupting the } \\
\text { pathways leading to the Th1-mediated destruction } \\
\text { of insulin-producing beta cells. }\end{array}$ & & Saunders et al., 2007 \\
\hline & Dirofilaria immitis & Prevents diabetes in NOD mice and increases lgE. & & Imai et al., 2001 \\
\hline
\end{tabular}

phosphorylation and activation of mitogen-activated protein kinases (MAPKs) such as p38 MAPK, Erk and JNK. In addition, the recruitment of MyD88 can activate the nuclear factor (NF)- $\kappa \mathrm{B}$ signaling pathway. Both the activation of MAPK kinases and NF- $\kappa \mathrm{B}$ signaling result in the production of pro-inflammatory molecules such as interleukin (IL)-6 and IL-12 (Melendez et al., 2007). Nevertheless, ES-62 is able to inhibit the JNK pathway and p38 MAPK pathway but stimulate the sustained activation of Erk, and Erk can inhibit the production of IL-12 via the transcription factor FOS (Lal et al., 1987; Goodridge et al., 2005b). Moreover, ES-62 can induce transient activation of the NF- $\kappa \mathrm{B}$ signaling pathway, which can induce a transformation from pro-inflammatory activity to an antiinflammatory TH2 response (Goodridge et al., 2005b; Kawai and Akira, 2010). Furthermore, the inhibition of JNK kinase by ES-62 can hinder the production of p35 subunit, the component of pro-inflammatory cytokines IL-6, IL-10, and TNF (Goodridge et al., 2005a).

ES-62 can modulate the activation of lymphocytes through the modulation of BCR and TCR. Normally, immunoreceptor tyrosine activation motifs (ITAMs) in BCR can be phosphorylated to induce the activation of the phosphoinositide 3-kinase (PI3K) and PLC $\gamma$ signaling pathways, both of which can induce the activation of PKCs such as aPKC, cPKC, and nPKC. In addition, phosphorylated ITAMs can recruit the Grb2/Sos complex, leading to the activation of Erk (Thomas et al., 2003). However, ES-62 can activate the SHP-1 tyrosine phosphatase to dephosphorylate and inactivate the ITAMs and consequently modulate the signaling pathways. Moreover, RasGAP and Pac-1 are recruited and inhibit Ras and Erk, respectively. ES-62 can also induce the degradation of PKCs to further modulate the PI3K and PLC $\gamma$ signaling pathway (Goodridge et al., 2007). Similarly, the phosphorylation of ITAMs in TCR can lead to the recruitment of PTKs and the subsequent activation of the PI3K and PLC $\gamma$ signaling pathway, both of which can induce the activation of PKCs (Deehan et al., 1998). ES-62 can modulate the PI3K and PLC $\gamma$ signaling pathways, but not the activation of PTKs, to promote the anti-inflammatory activity (Deehan et al., 2001).

ES-62 can also block mast cell degranulation, leading to inhibition of the release of pro-inflammatory cytokines such as prostaglandins and leukotrienes. Normally, an allergen or an allergen binding to FceRI and recruiting PKCs will lead to the activation of the PLD/SPHK1/calcium signaling pathway. As a result, the level of calcium is increased, which induces the degranulation of the mast cells and the initiation of an allergic response. In contrast, ES-62 binds to TLR4 and leads to the sequestration and degradation of $\mathrm{PKC} \alpha$, resulting in the uncoupling of the PLD/SPHK1/calcium signaling pathway. The level of calcium is decreased, which consequently suppresses the degranulation of mast cells (Harnett et al., 1998).

In addition, recent studies have demonstrated that ES-62 can also modulate complement activation. In the serum of individuals infected with $A$. viteae, ES-62 can bind to C-reactive protein (CRP) to form an ES-62-CRP-C1 complex (Marshall et al., 2005; McGrath et al., 2006). The flexible nature of PC attached to CRP leads to the uncoupling of $\mathrm{C} 1 \mathrm{~s}$ and $\mathrm{C} 4 \mathrm{~b}$, resulting in a failure of C2 cleavage. Moreover, ES-62 may be associated with the degradation of early complement components such as $\mathrm{C} 4$, which can also help suppress complement activation (Ahmed et al., 2016).

Animal experiments have also confirmed that ES-62 has a protective effect against some autoimmune diseases. The parasitic worm ES product has a protective effect against disease in a mouse collagen-induced arthritis model of rheumatoid arthritis (RA) by suppressing pathogenic IL-17 and upregulating IL-22 production by recruiting $\gamma \delta$ T cells (Pineda et al., 2014, 2015).

ES-62 can also reduce lupus-associated accelerated atherosclerosis in a mouse model. Although treatment with ES-62 cannot substantially modulate renal pathology, it can decrease anti-nuclear autoantibody levels, causing a 60\% reduction in aortic atherosclerotic lesions and an associated decrease in macrophages and fibrosis (Aprahamian et al., 2015). ES-62 also protects against ovalbumin-induced airway hyperresponsiveness in mice as a result of the covalently attached anti-inflammatory PC residues. Thus, PC plays a central role in the anti-inflammatory activity of ES-62 (Harnett and Harnett, 2010).

A library of 79 small-molecule analogs (SMAs) of ES-62 based around PC have been screened, and four synthetic ES-62-related SMAs (SMAs-11a, 11e, 11i, and 12b) were found to have similar modulatory effects to ES-62 and no immunogenicity. Sulforetype SMAs can modulate PAMP-mediated pro-inflammatory cytokine production and drive Th1/Th17 responses. In addition, SMAs can protect against allergies and some autoimmune diseases. For example, two SMAs, sulfone compounds termed 
11a and 12b, which are the major SMAs that have been discovered, have been shown to protect against clinically relevant allergens. The SMAs of ES-62 based around its active PC moiety also offer some protection against the development of pulmonary allergic responses to allergens (Janicova et al., 2016). Transferring DCs treated with SMAs to mice can significantly reduce the severity of collagen-induced arthritis, which is accompanied by a significant generation of Foxp $3^{+} \mathrm{CD} 4^{+}$ Treg cells and/or the production of IL-10, and a reduction in $\mathrm{IL}-17^{+}$cells in the draining lymph nodes (Lumb et al., 2017).

\section{Fasciola hepatica EXCRETORY-SECRETORY PRODUCTS (FHES, FHCL1, AND FHHDM)}

Fasciola hepatica excretory-secretory was found to be useful for diagnosing human fascioliasis (Haseeb et al., 2003). Using gel filtration chromatography, FHES can be divided into two components, FhCL1 and FhHDM. FhCL1 is a kind of cathepsin L cysteine protease and FhHDM is a peptide with a cathelicidin-like C-terminal alpha helix (Robinson et al., 2009, 2011).

Fasciola hepatica excretory-secretory has been demonstrated to protect against T1D in non-obese diabetic (NOD) mice (Lund et al., 2014). In NOD mice, there is infiltration of anti-autoantigen $\mathrm{CD}^{+} \mathrm{T}$ cells into the pancreatic lymph nodes (PLNs), which causes immune-system-mediated injury of the pancreatic islets (Jaakkola et al., 2003). In contrast, after administering FHES, plenty of IL-10-producing B cells rather than $\mathrm{CD}^{+} \mathrm{T}$ cells can be observed in PLNs, inhibiting the development of autoimmune diabetes in an IL-10-dependent manner. In addition, in NOD mice, an increased number of M1 macrophages are able to secrete IL-12, promoting autoantigen processing and a subsequent autoimmune response (Alleva et al., 2000). However, FHES can increase the level of regulatory M2 macrophages with increased Ym1, TGF$\beta$, Arg-1, and PD-L1 expression, leading to modulation of the immune reaction in the pancreatic islets. In addition, M2 macrophages can induce the activation of $\mathrm{CD} 4^{+} \mathrm{CD} 25^{+}$ Foxp3 Treg cells in a TGF- $\beta$-dependent manner (Lund et al., 2014).

Furthermore, FHES has been shown to protect against EAE in a murine model. FHES can enhance the $\mathrm{TH} 2$ response and reduce the $\mathrm{TH} 1 / \mathrm{TH} 17$ response, which consequently reduces the TH1 and TH17 cell infiltration into the central nervous system (CNS) (Finlay et al., 2016). Moreover, injecting FHES can increase anti-inflammatory cytokine levels, but the function of FHES is independent of anti-inflammatory cytokines such as IL-4 and IL-10. In contrast, the improvement of EAE symptoms depends on an increase in type 2 cytokines such as IL-5 and IL-33, which can induce the accumulation of eosinophils (Finlay et al., 2016). Previous research has demonstrated that the differentiation, maturation, and infiltration of eosinophils, which have immunomodulatory functions, are dependent on IL-5 (Ben Baruch-Morgenstern et al., 2014). As a result, after the injection of FHES, there is eosinophil infiltration into the
CNS, which helps to alleviate the immune response associated with EAE. In addition, IL-33 can improve the clinical symptoms of EAE and increase eosinophil infiltration and, after FHES administration to IL-33-/- mice, protection against EAE is changed, although the underlying mechanism remains elusive (Finlay et al., 2016).

Researchers have isolated FhCL1 and FhHDM to study their immunomodulatory effects. FhCL1 has been shown to suppress the production of IFN- $\gamma$. The protective effect of FheCL is associated with IL-4 because FheCL cannot function in an IL-4-defective murine model (O’Neill et al., 2001). Further study has shown that FheCL can inhibit the secretion of pro-inflammatory cytokines such as nitric oxide, IL-6, IL-12, and IFN- $\gamma$. The decreased level of pro-inflammatory cytokines is dependent on the inhibition of TLR3 and TLR4 via the suppression of the TRIF-dependent signaling pathway but not the MyD88-dependent pathway (Coakley et al., 2016). Interestingly, the inhibition of the pro-inflammatory signaling pathway depends on TLR3 degradation in endosomes, but why TLR3 degradation can affect the TLR4 signaling pathway is still unclear. The inhibition of nitric oxide, IL-6, IL-12, and IFN- $\gamma$ caused by FheCL has been taken advantage of to relieve the symptoms of endotoxic shock (Coakley et al., 2016).

As another component of FHES, FhHDM has been discovered to protect against atopic diseases (Alvarado et al., 2015). In a recent study, FhHDM was shown to alleviate the symptoms of T1D and EAE. However, FhHDM cannot inhibit the TH1 response or induce the $\mathrm{TH} 2$ response to modulate the immune response. The differences between FhHDM-1- and PBS-treated mice in the response to auto-antigens and in the production of cytokines by $\mathrm{T}$ cells are not significant (Lund et al., 2016). In addition, after the administration of FhHDM, there is no significant difference in the levels of pro-inflammatory cytokines, such as IFN- $\gamma$, IL-17, and TNF, and anti-inflammatory cytokines, such as IL-4 and IL-10. In contrast, FhHDM can inhibit the secretion of pro-inflammatory cytokines, such as TNF and IL-6, by macrophages in a dose-dependent manner instead of modulating the expression of co-stimulatory signaling pathways. According to previous research, although $\mathrm{CD}^{+}{ }^{+} \mathrm{T}$ cells play a key role in the progression of many autoimmune diseases such as T1D and EAE, the pro-inflammatory cytokines secreted by macrophages are involved in the initiation and progression of autoimmune disease via an interaction with $\mathrm{CD}^{+}{ }^{+}$T cells (Jun et al., 1999). Thus, FhHDM protects against autoimmune diseases such as T1D and EAE via the inhibition of pro-inflammatory cytokine-producing macrophages, instead of altering the macrophage phenotype or directly modulating the $\mathrm{T}$ cell function.

\section{Hymenolepis diminuta ANTIGEN (HDAG)}

Hymenolepis diminuta infection has been discovered to ameliorate the symptoms of dextran sodium sulfate (DSS)-induced colitis, which is a model of human inflammatory bowel disease (Reardon et al., 2001). HdAg has been shown 
to relieve DSS-induced colitis, with decreased expression of IFN- $\gamma$, IL-17, and TNF and increased expression of IL-10 (Reyes et al., 2016b). In a murine model of DSS-induced colitis, the administration of $\mathrm{HdAg}$ increases the level of CCR2-dependent immunoregulatory F4/80 ${ }^{+} \mathrm{Gr}-1^{\text {lo }}$ LyC6 $^{+}$monocyte-like cells in the peritoneal cavity. These cells, which can express programmed death ligand 1 (PD-L1), cannot modulate the proliferation of $\mathrm{T}$ cells directly but can enhance the production of IL-10 and IL-4 to suppress the immune response, which is a characteristic of myeloid-derived suppressor cells (MDSCs). However, whether the cells are MDSC or not is still unknown. In addition, the adoptive transfer of monocyte-like cells to HdAg-free mice can also inhibit the progression of DSS-induced colitis (Reyes et al., 2016b).

Matisz et al. (2015) tested whether DCs pulsed with HdAg can ameliorate the severity of hapten-induced colitis, just as direct HdAg administration can. The research has demonstrated that the administration of $H$. diminuta-pulsed (HD)-DCs can significantly ameliorate the severity and reduce the mortality of DSS-induced colitis, with an enhanced $\mathrm{TH} 2$ response and expression of TH2 cytokines such as IL-10, which is produced mainly by $\mathrm{CD} 4^{+} \mathrm{T}$ cells. The anti-colitis function of IL-10 appears to be a key, because there is no protection against colitis when HD-DCs are transferred into IL-10 knockout mice. In addition, further research has investigated the detailed mechanism of HD-DC function and demonstrated the importance of both IL-4 and IL-10 (Matisz et al., 2017). HD-DCs can produce IL-10, which induces recipient cells to secrete IL-4 and IL-10, and the IL-4 can then activate both the recipient cells and HD-DCs; HDDCs cannot directly produce IL-4. Both IL-4 and IL-10 have anti-colitic action.

\section{Trichinella spiralis EXCRETORY-SECRETORY MUSCLE LARVAE (ES L1)}

Prior infection with T. spiralis in a murine model of hapteninduced colitis has been shown to ameliorate the clinical symptoms of colitis (Khan et al., 2002). Motomura et al. (2009) extracted ES L1 to show that prior administration of the antigen can ameliorate the severity and reduce the mortality of hapten-induced colitis in a murine model. In their research, ES L1 was extracted from $T$. spiralis muscle L1 larvae. Prior submucosal application of the antigen enhances the $\mathrm{TH} 2$ response as well as the Treg response and reduces the $\mathrm{TH} 1$ response. The $\mathrm{TH} 2$ response can induce the production of IL-13 and the Treg response can induce the production of TGF- $\beta$, both of which help to modulate the aberrant immune response (Motomura et al., 2009).

Further examination has revealed that the administration of the antigen can lower the activity of myeloperoxidase (MPO) and the expression of IL-1 $\beta$ and iNOS. Previous research has demonstrated that MPO is located in various inflammatory cells such as neutrophils and it is regarded as a marker of inflammation (Smith and Castro, 1978). A decrease in MPO activity indicates a diminished immune response. IL-1 $\beta$ and iNOS play an important role in the initiation of inflammation, and downregulation indicates a lowered immune response. Further research has shown that prior administration of ES L1 can ameliorate EAE in a murine model, in a process in which CD $4^{+} \mathrm{CD} 25^{-}$Foxp $3^{+}$ regulatory cells play an important role (Radovic et al., 2015).

\section{AUTOCLAVED Schistosoma mansoni ANTIGEN (ASMA) AND AUTOCLAVED Trichinella spiralis ANTIGEN (ATSA)}

Researchers tested the protective effects of the administration of ASMA and ATSA in a rat model of adjuvant-induced arthritis (AA), which is similar to human RA (Eissa et al., 2016). The intradermal injection of ASMA or ATSA can ameliorate the clinical symptoms of AA with a significant increase in Foxp3 ${ }^{+}$Treg cells, and elevated levels of IL-17, IFN$\gamma$, and IL-10. IL-17 and IL-10 can inhibit the progression of AA, but IFN $-\gamma$ normally promotes an inflammatory response, which makes these findings controversial. However, a previous study showed that IFN- $\gamma$ may have an anti-inflammatory effect in certain situations, although the detailed mechanism has yet to be determined (Krakowski and Owens, 1996). Thus, the increase in IFN- $\gamma$ after treatment with ASMA or ATSA may have a protective effect on AA (Matthys et al., 1999).

\section{LACTO-N-FUCOPENTAOSE (LNFPIII)}

Lacto- $N$-fucopentaose is an antigen with a Lexis trisaccharide that is secreted by $S$. mansoni. Similar to ES-62, LNFPIII can induce a $\mathrm{TH} 2$ response via the sustained activation of Erk, transient activation of the NF- $\mathrm{B}$ signaling pathway, and inhibition of the JNK and p38 MAPK pathways (Thomas et al., 2003). Moreover, LNFPIII can interact with APCs through C-type receptors such as DC-specific ICAM3grabbing non-integrin (DC-SIGN) to induce anti-inflammatory activation (Van Liempt et al., 2004). Further research has shown that the interaction between LNFPIII and TLR4 is dependent on CD14 with clathrin to induce endocytosis of the complex (Srivastava et al., 2014; Tundup et al., 2015). In addition, LNFPIII can induce the production of IL-10 by B1 cells, which may modulate the alternative activation of macrophages. LNFPIII has been demonstrated to protect against hepatosteatosis, T1D, and EAE (Bhargava et al., 2012; Zhu et al., 2012).

\section{S. mansoni SOLUBLE EGG ANTIGEN (SEA)}

Schistosoma mansoni SEA has two components, IPSE and Omega-1. IPSE can trigger basophils to produce IL-4 and IL-13 via an interaction with IgE, leading to $\mathrm{TH} 2$ polarization ( $\mathrm{Li}$ et al., 2013). Structural analysis has shown that IPSE is a member of the 
$\beta \gamma$-crystallin superfamily that can interact with IgE via crystalline folds in a crosslink-independent pathway (Meyer et al., 2015). Another component of SEA, Omega-1, also has a protective effect against atopic diseases, which depends on its glycosylation and RNase activity. The glycan of Omega-1 can bind to the mannose receptor on DCs and mediate the internalization of SEA, while the RNase activity is associated with the degradation of ribosomal and messenger RNA, leading to the inhibition of protein synthesis (Eissa et al., 2016). It is thought that protein synthesis inhibition can induce $\mathrm{TH} 2$ polarization via an unknown mechanism. Furthermore, Omega-1 can induce the secretion of IL- $1 \beta$ by macrophages (which are stimulated by TLR2) via an interaction with the C-type lectin receptor Dectin-1 (Everts et al., 2012). The activation of Dectin-1 leads to the formation of a caspase- 8 inflammasome, which mediates the cleavage of pro-IL- $1 \beta$, leading to an increase in IL- $1 \beta$ secretion. In addition, further study has shown that omega-1 can induce the production of Foxp $3^{+}$Treg cells (Ferguson et al., 2015).

\section{Dirofilaria immitis DERIVED-ANTIGEN PRODUCT (DIAG)}

DiAg, a D. immitis-derived product, can induce the production of IL-4 and IL-10, leading to the inhibition of the TH1 response as well as IgG production in a murine model (Imai and Fujita, 2004). Moreover, with the help of IL-4, DiAg can induce the production of polyclonal IgE via interacting with CD40 on the surface of B cells. In addition, DiAg can trigger the production of antigen-non-specific IgE, which can saturate FceRI on the surface of mast cells. DiAg has also been discovered to relieve the symptoms of T1D in a murine model (Imai and Fujita, 2004).

\section{Schistosoma mansoni DERIVED CHEMOKINE BINDING PROTEIN (smCKBP)}

Schistosoma mansoni derived chemokine binding protein is a special protein that can interact with specific chemokines and prevent them from binding to and activating their receptors, leading to the inhibition of inflammatory cell activation and migration. smCKBP can interact with CXC-chemokine ligand 8 (CXCL8), CX3C-chemokine ligand 1 (CX3CL1), CCchemokine ligand 3 (CCL3), CCL2, and CCL5, of which CCL2 and CCL5 can regulate the activation of normal $\mathrm{T}$ cells. In particular, the interaction and inhibition of CXCL8 can prevent the migration and infiltration of neutrophils in a murine model of air pouch inflammation (Tundup et al., 2015).

\section{CYSTATIN}

Cystatin is a cysteine protease inhibitor that can be secreted by many parasites such as $A$. viteae and Onchocerca volvulus.
Cystatin can induce IL-10-producing macrophages, resulting in a decreased expression of APC co-stimulatory molecules such as CD86 (van der Kleij et al., 2002). The interference with antigen processing leads to the inhibition of $\mathrm{T}$ cell activation. Another cystatin derived from S. japonicum has been found to inhibit the activation of lysosomal cysteine protease, leading to the inhibition of antigen presentation by DCs. In addition, the activation of $\mathrm{CD}^{+} \mathrm{CD}^{+} 5^{+} \mathrm{Foxp}^{+} \mathrm{T}$ cells and the expression of IL- 4 and TGF- $\beta$ are significantly enhanced after the administration of cystatin (Chen et al., 2017). Cystatin has been found to relieve the symptoms of ovalbumin-induced airway hypersensitivity and DSS-induced colitis (Hartmann and Lucius, 2003; Schnoeller et al., 2008).

\section{SJ16}

Sj16 is a $S$. japonicum-derived protein (with a molecular weight of $16 \mathrm{kDa}$ ) that can be produced and secreted by all stages of S. japonicum. Research has confirmed that Sj16 is an important protein in the alleviation of inflammatory damage associated with cercariae penetration into the skin, and that it is intimately involved in the immune escape of S. japonicum ( $\mathrm{Hu}$ et al., 2009). Recombinant Sj16, produced by Escherichia coli, has a definite anti-inflammatory effect both in vivo and in vitro. $\mathrm{rSj} 16$ has been shown to dramatically suppress the thioglycolate-mediated recruitment of leukocytes to the peritoneal cavity of BALB/c mice by upregulating IL-10 and IL-1Ra transcripts and downregulating IL-12p35, IL-1 $\beta$, and MIP-2 transcripts ( $\mathrm{Hu}$ et al., 2012). Additionally, rSj16 has a potent immunomodulatory effect and it was found to significantly alleviate AA in a rat model (Sun et al., 2010). rSj16 was also reported to significantly induce IL-10 production by immature DCs and Th2-type responses in vitro (Sun et al., 2012b). Furthermore, rSj16 has been shown to increase $\mathrm{CD} 4{ }^{+} \mathrm{CD} 25^{+}$regulatory $\mathrm{T}$ cells in splenic cells (Sun et al., 2012a). Recently, animal experiments confirmed that $\mathrm{rSj} 16$ protects against DSS-induced colitis by inhibiting the peroxisome proliferator-activated receptor $\alpha$ (PPAR- $\alpha$ ) signaling pathway (Wang et al., 2017).

\section{SM16}

Sm16, a $16.8-\mathrm{kDa}$ protein secreted by the parasite $S$. mansoni (cercariae and schistosomula) during skin penetration, has been reported to have anti-inflammatory and immunomodulatory activities (Ramaswamy et al., 1994; Kalyanasundaram et al., 1995). In vitro studies have shown that Sm16 downregulates ICAM-1 expression on endothelial cells, prevents lymphoproliferation, and suppresses IL-1a expression in human keratinocytes (Kalyanasundaram et al., 1995; Ramaswamy et al., 1998). Moreover, Sm16 can prevent LPS-induced neutrophil infiltration in the dermis (Rao and Ramaswamy, 2000). Sm16 potently inhibits the cytokine response to the Toll-like receptor ligands LPS and polyinosinic:polycytidylic acid, and it also inhibits the degradation of the IRAK1 signaling 
protein in LPS-stimulated monocytes (Brannstrom et al., 2009). Additionally, Sm16 may contribute to limit dermal inflammation after percutaneous infection with S. mansoni cercariae (Sanin and Mountford, 2015).

\section{DISCUSSION}

During the long history of the co-evolution of humans and parasites, parasites have adopted a parasitic lifecycle and gradually become exquisitely well-adapted to the host immune system, and they can live in the host for a long time by modulating the host immune response. Epidemiological investigation, animal models, and several clinical trials indicate that infections involving some parasites, especially helminths such as S. mansoni, S. japonicum, Trichuris suis, Clonorchis sinensis, $H$. diminuta, and Ascaris lumbricoides, can prevent or treat autoimmune and atopic diseases to a certain extent. There is growing interest in identifying the important parasitederived immunomodulation molecules for use as autoimmune and atopic disease treatments, because directly using parasites as treatments may cause parasitic diseases and it would be difficult to make the treatments widely accepted by patients.

Parasite-derived immunomodulation molecules have different mechanisms of hampering the host immune response to create a tolerant environment not only to ensure their own survival but also to protect the host against excessive inflammation by reducing the immune response and inhibiting the progression of atopic diseases. They can exert their immunoregulatory functions by modulating cells of both the innate and adaptive immune systems. Generally, most parasites can promote a typical Th2 response and modulate Th1/Th17 differentiation, leading to a significant increase in the secretion of Th2-related cytokines such as IL-4, IL-5, IL-9, IL-10, IL-13, and IgE, and a decrease the secretion of Th1/Th17-related cytokines such as IL-6, IL-12, TNF- $\alpha$, IFN-r, and IL-17 (Pulendran et al., 2010). For example, ES-62 derived from A. viteae has been discovered to promote a $\mathrm{TH} 2$ response by interacting with TLR4, modulate lymphocyte activation by modulating BCR and TCR, block mast cell degranulation (leading to the release of pro-inflammatory cytokines such as prostaglandins and leukotrienes), and modulate complement activation to protect against atopic diseases. ES-62 has been used to treat rheumatoid arthritis, systemic lupus erythematosus, ovalbumin-induced airway hypersensitivity, oxazolone-induced contact sensitivity, and so on (Lumb et al., 2017).

Parasite-derived immunomodulation molecules can evoke a regulatory or tolerogenic phenotype among immune cells including DCs, B cells, T cells, and macrophages. Helminth proteins can influence DC differentiation toward a tolerogenic phenotype by modulating the DC signaling pathway. These kinds of phenotypes, such as M2 macrophages and tolerogenic DCs, can shift a Th1/Th17 response to a Th2 response, and they have been shown to be essential for the prevention of autoimmunity
(Versini et al., 2015). Some proteins also influence the innate immune cells such as ILCs. ILCs play a role in host-initiated protective immunity against helminths and are able to initiate allergies (Spits et al., 2013; Versini et al., 2015). In addition to direct regulation of the immune system, parasite-derived proteins can also indirectly regulate the immune system by modulating the bacterial composition of the gut microflora (Walk et al., 2010; Lee et al., 2014; Zaiss et al., 2015).

However, owing to the immunogenicity of parasite-derived molecules, these potential treatments may be harmful to some people. Analogs of parasite-derived molecules have been designed to function as immune modulators that have less or even no immunogenicity. For example, SMAs have been designed according to the structure of PC, and they have similar functions to PC but no immunogenicity. One of the SMAs, 11a, has been shown to inhibit the progression of collagen-induced arthritis in a murine model.

As the incidence and harmfulness of allergies and autoimmunity have been rising all over the world, the design of new drugs to prevent and treat these diseases should not be delayed. Parasites have long parasitized the human body and have lived in peace with their hosts by modulating the human immune response. The administration of parasitederived molecules is considered more effective and safer to humans than other immunomodulatory drugs. However, research on parasite-derived molecules is just the beginning. Most experiments to investigate the functions of parasite-derived proteins, in terms of their effects on atopic diseases, have involved animal models. Thus, production quality standards and effective dosages of the parasite-derived proteins need to be confirmed. In addition, the precise mechanisms of these key proteins need to be explored further. There are still insufficient studies on the administration of the molecules among humans. From parasites to pills, there is still a long way to go.

\section{AUTHOR CONTRIBUTIONS}

This manuscript was designed by XS, drafted by ZW, LW, and YT, and revised by XS. All authors participated in critical revision of the manuscript and approved the final manuscript.

\section{ACKNOWLEDGMENTS}

This review was supported by grants from the National High Technology Research and Development Program of China (Grant No. 2015AA020934), the Pearl River Nova Program of Guangzhou (Grant No. 201710010030), the National Natural Science Foundation of China (Grant No. 81572014), the Doctoral Program of Higher Education of China (Grant No. 20120171120049), and the National Science Foundation of Guangdong Province (Grant No. S2012040007256). 


\section{REFERENCES}

Abdel-Maksoud, M. A., Abdel-Ghaffar, F. A., El-Amir, A., Al-Quraishy, S., and Badr, G. (2016). Infection with Plasmodium chabaudi diminishes plasma immune complexes and ameliorates the histopathological alterations in different organs of female BWF1 lupus mice. Eur. Rev. Med. Pharmacol. Sci. 20, 733-744.

Agrawal, S., Agrawal, A., Doughty, B., Gerwitz, A., Blenis, J., Van Dyke, T., et al. (2003). Cutting edge: different Toll-like receptor agonists instruct dendritic cells to induce distinct $\mathrm{Th}$ responses via differential modulation of extracellular signal-regulated kinase-mitogen-activated protein kinase and c-Fos. J. Immunol. 171, 4984-4989. doi: 10.4049/jimmunol.171.10. 4984

Ahmed, U. K., Maller, N. C., Iqbal, A. J., Al-Riyami, L., Harnett, W., and Raynes, J. G. (2016). The carbohydrate-linked phosphorylcholine of the parasitic nematode product ES-62 modulates complement activation. J. Biol. Chem. 291, 11939-11953. doi: 10.1074/jbc.M115.702746

Alleva, D. G., Pavlovich, R. P., Grant, C., Kaser, S. B., and Beller, D. I. (2000). Aberrant macrophage cytokine production is a conserved feature among autoimmune-prone mouse strains: elevated interleukin (IL)-12 and an imbalance in tumor necrosis factor-alpha and IL-10 define a unique cytokine profile in macrophages from young nonobese diabetic mice. Diabetes Metab. Res. Rev. 49, 1106-1115. doi: 10.2337/diabetes.49.7.1106

Alvarado, R., O’Brien, B., Tanaka, A., Dalton, J. P., and Donnelly, S. (2015). A parasitic helminth-derived peptide that targets the macrophage lysosome is a novel therapeutic option for autoimmune disease. Immunobiology 220, 262-269. doi: 10.1016/j.imbio.2014.11.008

Aprahamian, T. R., Zhong, X., Amir, S., Binder, C. J., Chiang, L. K., Al-Riyami, L., et al. (2015). The immunomodulatory parasitic worm product ES-62 reduces lupus-associated accelerated atherosclerosis in a mouse model. Int. J. Parasitol. 45, 203-207. doi: 10.1016/j.ijpara.2014.12.006

Badr, G., Sayed, A., Abdel-Maksoud, M. A., Mohamed, A. O., El-Amir, A., AbdelGhaffar, F. A., et al. (2015). Infection of female BWF1 lupus mice with malaria parasite attenuates B cell autoreactivity by modulating the CXCL12/CXCR4 axis and its downstream signals PI3K/AKT, NFkappaB and ERK. PLOS ONE 10:e0125340. doi: 10.1371/journal.pone.0125340

Ben Baruch-Morgenstern, N., Shik, D., Moshkovits, I., Itan, M., Karo-Atar, D., Bouffi, C., et al. (2014). Paired immunoglobulin-like receptor A is an intrinsic, self-limiting suppressor of IL-5-induced eosinophil development. Nat. Immunol. 15, 36-44. doi: 10.1038/ni.2757

Bhargava, P., Li, C., Stanya, K. J., Jacobi, D., Dai, L., Liu, S., et al. (2012). Immunomodulatory glycan LNFPIII alleviates hepatosteatosis and insulin resistance through direct and indirect control of metabolic pathways. Nat. Med. 18, 1665-1672. doi: 10.1038/nm.2962

Bing, S. J., Ha, D., Ahn, G., Cho, J., Kim, A., Park, S. K., et al. (2015). Galectin isolated from parasite inhibits remission of experimental autoimmune encephalomyelitis by up-regulating autoantibody. Clin. Exp. Immunol. 180, 419-431. doi: 10.1111/cei.12594

Bodammer, P., Waitz, G., Loebermann, M., Holtfreter, M. C., Maletzki, C., Krueger, M. R., et al. (2011). Schistosoma mansoni infection but not egg antigen promotes recovery from colitis in outbred NMRI mice. Dig. Dis. Sci. 56, 70-78. doi: 10.1007/s10620-010-1237-y

Brannstrom, K., Sellin, M. E., Holmfeldt, P., Brattsand, M., and Gullberg, M. (2009). The Schistosoma mansoni protein Sm16/SmSLP/SmSPO-1 assembles into a nine-subunit oligomer with potential To inhibit Tolllike receptor signaling. Infect. Immun. 77, 1144-1154. doi: 10.1128/IAI. 01126-08

Carranza, F., Falcon, C. R., Nunez, N., Knubel, C., Correa, S. G., Bianco, I., et al. (2012). Helminth antigens enable CpG-activated dendritic cells to inhibit the symptoms of collagen-induced arthritis through Foxp3+ regulatory $\mathrm{T}$ cells. PLOS ONE 7:e40356. doi: 10.1371/journal.pone.0040356

Chen, L., He, B., Hou, W., and He, L. (2017). Cysteine protease inhibitor of Schistosoma japonicum - A parasite-derived negative immunoregulatory factor. Parasitol. Res. 116, 901-908. doi: 10.1007/s00436-016-5363-0

Coakley, G., Buck, A. H., and Maizels, R. M. (2016). Host parasite communications-Messages from helminths for the immune system: parasite communication and cell-cell interactions. Mol. Biochem. Parasitol. 208, 33-40. doi: 10.1016/j.molbiopara.2016.06.003
Cooke, A. (2009). Review series on helminths, immune modulation and the hygiene hypothesis: how might infection modulate the onset of type 1 diabetes? Immunology 126, 12-17. doi: 10.1111/j.1365-2567.2008.03009.x

Coronado, S., Barrios, L., Zakzuk, J., Regino, R., Ahumada, V., Franco, L., et al. (2017). A recombinant cystatin from Ascaris lumbricoides attenuates inflammation of DSS-induced colitis. Parasite Immunol. 39, e12425. doi: $10.1111 /$ pim. 12425

de Ruiter, K., Tahapary, D. L., Sartono, E., Soewondo, P., Supali, T., Smit, J. W. A., et al. (2017). Helminths, hygiene hypothesis and type 2 diabetes. Parasite Immunol. 39, e12404. doi: 10.1111/pim.12404

Deehan, M. R., Frame, M. J., Parkhouse, R. M., Seatter, S. D., Reid, S. D., Harnett, M. M., et al. (1998). A phosphorylcholine-containing filarial nematodesecreted product disrupts B lymphocyte activation by targeting key proliferative signaling pathways. J. Immunol. 160, 2692-2699.

Deehan, M. R., Harnett, W., and Harnett, M. M. (2001). A filarial nematodesecreted phosphorylcholine-containing glycoprotein uncouples the B cell antigen receptor from extracellular signal-regulated kinase-mitogen-activated protein kinase by promoting the surface Ig-mediated recruitment of Src homology 2 domain-containing tyrosine phosphatase-1 and Pac-1 mitogenactivated kinase-phosphatase. J. Immunol. 166, 7462-7468. doi: 10.4049/ jimmunol.166.12.7462

Ditgen, D., Anandarajah, E. M., Meissner, K. A., Brattig, N., Wrenger, C., and Liebau, E. (2014). Harnessing the helminth secretome for therapeutic immunomodulators. BioMed Res. Int. 2014:964350. doi: 10.1155/2014/964350

Driss, V., El Nady, M., Delbeke, M., Rousseaux, C., Dubuquoy, C., Sarazin, A., et al. (2016). The schistosome glutathione S-transferase P28GST, a unique helminth protein, prevents intestinal inflammation in experimental colitis through a Th2-type response with mucosal eosinophils. Mucosal Immunol. 9, 322-335. doi: $10.1038 / \mathrm{mi} .2015 .62$

Eissa, M. M., Mostafa, D. K., Ghazy, A. A., El Azzouni, M. Z., Boulos, L. M., and Younis, L. K. (2016). Anti-arthritic activity of schistosoma mansoni and trichinella spiralis derived-antigens in adjuvant arthritis in rats: role of FOXP3+ treg cells. PLOS ONE 11:e0165916. doi: 10.1371/journal.pone.0165916

Elliott, D. E., and Weinstock, J. V. (2017). Nematodes and human therapeutic trials for inflammatory disease. Parasite Immunol. 39:e12407. doi: 10.1111/pim.12407

Erb, K. J. (2009). Can helminths or helminth-derived products be used in humans to prevent or treat allergic diseases? Trends Immunol. 30, 75-82. doi: 10.1016/j. it.2008.11.005

Everts, B., Hussaarts, L., Driessen, N. N., Meevissen, M. H., Schramm, G., van der Ham, A. J., et al. (2012). Schistosome-derived omega-1 drives Th2 polarization by suppressing protein synthesis following internalization by the mannose receptor. J. Exp. Med. 209, 1753-1767. doi: 10.1084/jem.201 11381

Farias, A. S., Talaisys, R. L., Blanco, Y. C., Lopes, S. C., Longhini, A. L., Pradella, F., et al. (2011). Regulatory T cell induction during Plasmodium chabaudi infection modifies the clinical course of experimental autoimmune encephalomyelitis. PLOS ONE 6:e17849. doi: 10.1371/journal.pone.0017849

Ferguson, B. J., Newland, S. A., Gibbs, S. E., Tourlomousis, P., Fernandes dos Santos, P., Patel, M. N., et al. (2015). The Schistosoma mansoni T2 ribonuclease omega-1 modulates inflammasome-dependent IL-1beta secretion in macrophages. Int. J. Parasitol. 45, 809-813. doi: 10.1016/j.ijpara.2015.08.005

Finlay, C. M., Stefanska, A. M., Walsh, K. P., Kelly, P. J., Boon, L., Lavelle, E. C., et al. (2016). Helminth products protect against autoimmunity via innate type 2 Cytokines IL-5 and IL-33, which promote Eosinophilia. J. Immunol. 196, 703-714. doi: 10.4049/jimmunol.1501820

Garg, S. K., Croft, A. M., and Bager, P. (2014). Helminth therapy (worms) for induction of remission in inflammatory bowel disease. Cochrane Database Syst. Rev. 1:CD009400. doi: 10.1002/14651858.CD009400.pub2

Goodridge, H. S., Deehan, M. R., Harnett, W., and Harnett, M. M. (2005a). Subversion of immunological signalling by a filarial nematode phosphorylcholine-containing secreted product. Cell. Signal. 17, 11-16.

Goodridge, H. S., McGuiness, S., Houston, K. M., Egan, C. A., Al-Riyami, L., Alcocer, M. J., et al. (2007). Phosphorylcholine mimics the effects of ES-62 on macrophages and dendritic cells. Parasite Immunol. 29, 127-137. doi: 10.1111/ j.1365-3024.2006.00926.x

Goodridge, H. S., Stepek, G., Harnett, W., and Harnett, M. M. (2005b). Signalling mechanisms underlying subversion of the immune response by the filarial nematode secreted product ES-62. Immunology 115, 296-304. 
Greenwood, B. M. (1969). Polyarthritis in Western Nigeria. I. Rheumatoid arthritis. Ann. Rheum. Dis. 28, 488-496. doi: 10.1136/ard.28.5.488

Greenwood, B. M., Herrick, E. M., and Voller, A. (1970). Suppression of autoimmune disease in NZB and (NZB x NZW) F1 hybrid mice by infection with malaria. Nature 226, 266-267. doi: 10.1038/226266a0

Gruden-Movsesijan, A., Ilic, N., Mostarica-Stojkovic, M., Stosic-Grujicic, S., Milic, M., and Sofronic-Milosavljevic, L. (2008). Trichinella spiralis: modulation of experimental autoimmune encephalomyelitis in DA rats. Exp. Parasitol. 118, 641-647. doi: 10.1016/j.exppara.2007.12.003

Gruden-Movsesijan, A., Ilic, N., Mostarica-Stojkovic, M., Stosic-Grujicic, S., Milic, M., and Sofronic-Milosavljevic, L. (2010). Mechanisms of modulation of experimental autoimmune encephalomyelitis by chronic Trichinella spiralis infection in dark agouti rats. Parasite Immunol. 32, 450-459. doi: 10.1111/j. 1365-3024.2010.01207.x

Haarder, S., Kania, P. W., Holm, T. L., von Gersdorff Jorgensen, L., and Buchmann, K. (2017). Effect of ES-products from Anisakis (Nematoda: Anisakidae) on experimentally induced colitis in adult zebrafish. Parasite Immunol. 39, e12456. doi: 10.1111/pim.12456

Hansen, C. S., Hasseldam, H., Bacher, I. H., Thamsborg, S. M., Johansen, F. F., and Kringel, H. (2017). Trichuris suis secrete products that reduce disease severity in a multiple sclerosis model. Acta Parasitol. 62, 22-28. doi: 10.1515/ap-2017-0002

Harnett, M. M., Deehan, M. R., Williams, D. M., and Harnett, W. (1998). Induction of signalling anergy via the T-cell receptor in cultured Jurkat $\mathrm{T}$ cells by pre-exposure to a filarial nematode secreted product. Parasite Immunol. 20, 551-563. doi: 10.1046/j.1365-3024.1998.00181.x

Harnett, W., and Harnett, M. M. (2010). Helminth-derived immunomodulators: can understanding the worm produce the pill? Nat. Rev. Immunol. 10, 278-284. doi: $10.1038 /$ nri2730

Hartmann, S., and Lucius, R. (2003). Modulation of host immune responses by nematode cystatins. Int. J. Parasitol. 33, 1291-1302. doi: 10.1016/S00207519(03)00163-2

Hasby, E. A., Hasby Saad, M. A., Shohieb, Z., and El Noby, K. (2015). FoxP3+ T regulatory cells and immunomodulation after Schistosoma mansoni egg antigen immunization in experimental model of inflammatory bowel disease. Cell Immunol. 295, 67-76. doi: 10.1016/j.cellimm.2015.02.013

Haseeb, A. N., el-Shazly, A. M., Arafa, M. A., and Morsy, A. T. (2003). Evaluation of excretory/secretory Fasciola (Fhes) antigen in diagnosis of human fascioliasis. J. Egypt. Soc. Parasitol. 33, 123-138.

Heylen, M., Ruyssers, N. E., De Man, J. G., Timmermans, J. P., Pelckmans, P. A., Moreels, T. G., et al. (2014a). Worm proteins of Schistosoma mansoni reduce the severity of experimental chronic colitis in mice by suppressing colonic proinflammatory immune responses. PLOS ONE 9:e110002. doi: 10.1371 /journal.pone. 0110002

Heylen, M., Ruyssers, N. E., Gielis, E. M., Vanhomwegen, E., Pelckmans, P. A., Moreels, T. G., et al. (2014b). Of worms, mice and man: an overview of experimental and clinical helminth-based therapy for inflammatory bowel disease. Pharmacol. Ther. 143, 153-167. doi: 10.1016/j.pharmthera.2014.02.011

Houston, K. M., and Harnett, W. (2004). Structure and synthesis of nematode phosphorylcholine-containing glycoconjugates. Parasitology 129, 655-661. doi: $10.1017 / S 0031182004006171$

Hu, S., Wu, Z., Yang, L., and Fung, M. C. (2009). Molecular cloning and expression of a functional anti-inflammatory protein, $\mathrm{Sj} 16$, of Schistosoma japonicum. Int. J. Parasitol. 39, 191-200. doi: 10.1016/j.ijpara.2008.06.017

Hu, S., Yang, L., Wu, Z., Wong, C. S., and Fung, M. C. (2012). Suppression of adaptive immunity to heterologous antigens by SJ16 of Schistosoma japonicum. J. Parasitol. 98, 274-283. doi: 10.1645/GE-2692.1

Imai, S., and Fujita, K. (2004). Molecules of parasites as immunomodulatory drugs. Curr. Top. Med. Chem. 4, 539-552. doi: 10.2174/1568026043451285

Imai, S., Tezuka, H., and Fujita, K. (2001). A factor of inducing IgE from a filarial parasite prevents insulin-dependent diabetes mellitus in nonobese diabetic mice. Biochem. Biophys. Res. Commun. 286, 1051-1058. doi: 10.1006/bbrc.2001. 5471

Jaakkola, I., Jalkanen, S., and Hanninen, A. (2003). Diabetogenic T cells are primed both in pancreatic and gut-associated lymph nodes in NOD mice. Eur. J. Immunol. 33, 3255-3264. doi: 10.1002/eji.200324405

Jang, S. W., Cho, M. K., Park, M. K., Kang, S. A., Na, B. K., Ahn, S. C., et al. (2011). Parasitic helminth cystatin inhibits DSS-induced intestinal inflammation via
IL-10(+)F4/80(+) macrophage recruitment. Korean J. Parasitol. 49, 245-254. doi: $10.3347 / \mathrm{kjp} .2011 .49 .3 .245$

Janicova, L., Rzepecka, J., Rodgers, D. T., Doonan, J., Bell, K. S., Lumb, F. E., et al. (2016). Testing small molecule analogues of the Acanthocheilonema viteae immunomodulator ES-62 against clinically relevant allergens. Parasite Immunol. 38, 340-351. doi: 10.1111/pim.12322

Jun, H. S., Yoon, C. S., Zbytnuik, L., van Rooijen, N., and Yoon, J. W. (1999). The role of macrophages in T cell-mediated autoimmune diabetes in nonobese diabetic mice. J. Exp. Med. 189, 347-358. doi: 10.1084/jem.189.2.347

Kalyanasundaram, R., Salafsky, B., Lykken, M., and Shibuya, T. (1995). Modulation of IL-1alpha, IL-1beta and IL-1RA production in human keratinocytes by schistosomulae of Schistosoma mansoni. Immunol. Infect. Dis. 5, 100-107.

Kawai, T., and Akira, S. (2010). The role of pattern-recognition receptors in innate immunity: update on Toll-like receptors. Nat. Immunol. 11, 373-384. doi: $10.1038 /$ ni. 1863

Khan, W. I., Blennerhasset, P. A., Varghese, A. K., Chowdhury, S. K., Omsted, P., Deng, Y., et al. (2002). Intestinal nematode infection ameliorates experimental colitis in mice. Infect. Immun. 70, 5931-5937. doi: 10.1128/IAI.70.11.59315937.2002

Krakowski, M., and Owens, T. (1996). Interferon-gamma confers resistance to experimental allergic encephalomyelitis. Eur. J. Immunol. 26, 1641-1646. doi: 10.1002/eji.1830260735

Kron, M. A., Metwali, A., Vodanovic-Jankovic, S., and Elliott, D. (2013). Nematode asparaginyl-tRNA synthetase resolves intestinal inflammation in mice with T-cell transfer colitis. Clin. Vaccine Immunol. 20, 276-281. doi: 10.1128/CVI. 00594- 12

La Flamme, A. C., Ruddenklau, K., and Backstrom, B. T. (2003). Schistosomiasis decreases central nervous system inflammation and alters the progression of experimental autoimmune encephalomyelitis. Infect. Immun. 71, 4996-5004. doi: 10.1128/IAI.71.9.4996-5004.2003

Lal, R. B., Paranjape, R. S., Briles, D. E., Nutman, T. B., and Ottesen, E. A. (1987). Circulating parasite antigen(s) in lymphatic filariasis: use of monoclonal antibodies to phosphocholine for immunodiagnosis. J. Immunol. 138, 3454-3460.

Lee, S. C., Tang, M. S., Lim, Y. A., Choy, S. H., Kurtz, Z. D., Cox, L. M., et al. (2014). Helminth colonization is associated with increased diversity of the gut microbiota. PLOS Negl. Trop. Dis. 8:e2880. doi: 10.1371/journal.pntd.0002880

Li, L., Xie, H., Wang, M., Qu, J., Cha, H., Yang, Q., et al. (2017). Characteristics of IL-9 induced by Schistosoma japonicum infection in C57BL/6 mouse liver. Sci. Rep. 7, 2343. doi: 10.1038/s41598-017-02422-8

Li, S., Ren, W., Li, W., Zhao, N., Ma, G., Gong, P., et al. (2013). A shift to Th2 immune response caused by constitutive expression of IPSE/alpha- 1 in transfected pig fibroblasts in mice. Vet. Immunol. Immunopathol. 152, 269-276. doi: 10.1016/j.vetimm.2012.12.019

Liu, F., Cheng, W., Pappoe, F., Hu, X., Wen, H., Luo, Q., et al. (2016). Schistosoma japonicum cystatin attenuates murine collagen-induced arthritis. Parasitol. Res. 115, 3795-3806. doi: 10.1007/s00436-016-5140-0

Lumb, F. E., Doonan, J., Bell, K. S., Pineda, M. A., Corbet, M., Suckling, C. J., et al. (2017). Dendritic cells provide a therapeutic target for synthetic small molecule analogues of the parasitic worm product, ES-62. Sci. Rep. 7, 1704. doi: 10.1038/s41598-017-01651-1

Lund, M. E., Greer, J., Dixit, A., Alvarado, R., McCauley-Winter, P., To, J., et al. (2016). A parasite-derived 68-mer peptide ameliorates autoimmune disease in murine models of Type 1 diabetes and multiple sclerosis. Sci. Rep. 6:37789. doi: 10.1038/srep37789

Lund, M. E., O’Brien, B. A., Hutchinson, A. T., Robinson, M. W., Simpson, A. M., Dalton, J. P., et al. (2014). Secreted proteins from the helminth Fasciola hepatica inhibit the initiation of autoreactive $\mathrm{T}$ cell responses and prevent diabetes in the NOD mouse. PLOS ONE 9:e86289. doi: 10.1371/journal.pone.0086289

Maizels, R. M., and McSorley, H. J. (2016). Regulation of the host immune system by helminth parasites. J. Allergy Clin. Immunol. 138, 666-675. doi: 10.1016/j. jaci.2016.07.007

Marshall, F. A., Grierson, A. M., Garside, P., Harnett, W., and Harnett, M. M. (2005). ES-62, an immunomodulator secreted by filarial nematodes, suppresses clonal expansion and modifies effector function of heterologous antigenspecific T cells in vivo. J. Immunol. 175, 5817-5826. doi: 10.4049/jimmunol.175. 9.5817 
Matisz, C. E., Faz-Lopez, B., Thomson, E., Al Rajabi, A., Lopes, F., Terrazas, L. I., et al. (2017). Suppression of colitis by adoptive transfer of helminth antigentreated dendritic cells requires interleukin-4 receptor-alpha signaling. Sci. Rep. 7:40631. doi: 10.1038/srep40631

Matisz, C. E., Leung, G., Reyes, J. L., Wang, A., Sharkey, K. A., and McKay, D. M. (2015). Adoptive transfer of helminth antigen-pulsed dendritic cells protects against the development of experimental colitis in mice. Eur. J. Immunol. 45, 3126-3139. doi: 10.1002/eji.201545579

Matthys, P., Vermeire, K., Mitera, T., Heremans, H., Huang, S., Schols, D., et al. (1999). Enhanced autoimmune arthritis in IFN-gamma receptor-deficient mice is conditioned by mycobacteria in Freund's adjuvant and by increased expansion of Mac-1+ myeloid cells. J. Immunol. 163, 3503-3510.

McGrath, F. D., Brouwer, M. C., Arlaud, G. J., Daha, M. R., Hack, C. E., and Roos, A. (2006). Evidence that complement protein C1q interacts with C-reactive protein through its globular head region. J. Immunol. 176, 2950-2957. doi: 10.4049/ jimmunol.176.5.2950

Melendez, A. J., Harnett, M. M., Pushparaj, P. N., Wong, W. S., Tay, H. K., McSharry, C. P., et al. (2007). Inhibition of Fc epsilon RI-mediated mast cell responses by ES-62, a product of parasitic filarial nematodes. Nat. Med. 13, 1375-1381. doi: 10.1038/nm1654

Meyer, N. H., Mayerhofer, H., Tripsianes, K., Blindow, S., Barths, D., Mewes, A., et al. (2015). A Crystallin Fold in the Interleukin-4-inducing Principle of Schistosoma mansoni Eggs (IPSE/alpha-1) mediates IgE binding for antigenindependent basophil activation. J. Biol. Chem. 290, 22111-22126. doi: 10.1074/ jbc.M115.675066

Miyake, K., Adachi, K., Watanabe, M., Sasatomi, Y., Ogahara, S., Abe, Y., et al. (2014). Parasites alter the pathological phenotype of lupus nephritis. Autoimmunity 47, 538-547. doi: 10.3109/08916934.2014.929669

Motomura, Y., Wang, H., Deng, Y., El-Sharkawy, R. T., Verdu, E. F., and Khan, W. I. (2009). Helminth antigen-based strategy to ameliorate inflammation in an experimental model of colitis. Clin. Exp. Immunol. 155, 88-95. doi: 10.1111/ j.1365-2249.2008.03805.x

O’Neill, S. M., Mills, K. H., and Dalton, J. P. (2001). Fasciola hepatica cathepsin L cysteine proteinase suppresses Bordetella pertussis-specific interferon-gamma production in vivo. Parasite Immunol. 23, 541-547. doi: 10.1046/j.1365-3024. 2001.00411.x

Pineda, M. A., Eason, R. J., Harnett, M. M., and Harnett, W. (2015). From the worm to the pill, the parasitic worm product ES-62 raises new horizons in the treatment of rheumatoid arthritis. Lupus 24, 400-411. doi: 10.1177/ 0961203314560004

Pineda, M. A., Rodgers, D. T., Al-Riyami, L., Harnett, W., and Harnett, M. M. (2014). ES-62 protects against collagen-induced arthritis by resetting interleukin-22 toward resolution of inflammation in the joints. Arthritis Rheumatol. 66, 1492-1503. doi: 10.1002/art.38392

Pulendran, B., Tang, H., and Manicassamy, S. (2010). Programming dendritic cells to induce $\mathrm{T}(\mathrm{H}) 2$ and tolerogenic responses. Nat. Immunol. 11, 647-655. doi: $10.1038 /$ ni.1894

Radovic, I., Gruden-Movsesijan, A., Ilic, N., Cvetkovic, J., Mojsilovic, S., Devic, M., et al. (2015). Immunomodulatory effects of Trichinella spiralisderived excretory-secretory antigens. Immunol. Res. 61, 312-325. doi: 10.1007/ s12026-015-8626-4

Ramaswamy, K., Potluri, S., Ramaswamy, P., Ebbing, A., He, Y., Kumar, P., et al. (1998). "Immune evasion by Schistosoma mansoni: characterization of Sm 16.8 an anti-inflammatory protein produced by the skin stage schistosomulum," in Proceedings of the 9th International Conference on Parasitology, Paris, 597-603.

Ramaswamy, K., Salafsky, B., Potluri, S., He, Y. -X., Li, J. -W., and Shibuya, T. (1994). Secretion of an anti-inflammatory, immunomodulatory factor by Schistosomulae of Schistosoma mansoni. J. Inflamm. 46, 13-22.

Rao, K., and Ramaswamy, K. (2000). Cloning and expression of a gene encoding Sm16, an anti-inflammatory protein from Schistosoma mansoni. Mol. Biochem. Parasitol. 108, 101-108. doi: 10.1016/S0166-6851(00)00209-7

Reardon, C., Sanchez, A., Hogaboam, C. M., and McKay, D. M. (2001). Tapeworm infection reduces epithelial ion transport abnormalities in murine dextran sulfate sodium-induced colitis. Infect. Immun. 69, 4417-4423. doi: 10.1128/IAI. 69.7.4417-4423.2001

Reddy, S. M., Reddy, P. M., Amdare, N., Khatri, V., Tarnekar, A., Goswami, K., et al. (2017). Filarial abundant larval transcript protein ALT-2: an immunomodulatory therapeutic agent for type 1 diabetes. Indian J. Clin. Biochem. 32, 45-52. doi: 10.1007/s12291-016-0572-y

Reyes, J. L., Fernando, M. R., Lopes, F., Leung, G., Mancini, N. L., Matisz, C. E., et al. (2016a). IL-22 restrains tapeworm-mediated protection against experimental colitis via regulation of IL-25 expression. PLOS Pathog. 12:e1005481. doi: 10.1371/journal.ppat.1005481

Reyes, J. L., Lopes, F., Leung, G., Mancini, N. L., Matisz, C. E., Wang, A., et al. (2016b). Treatment with cestode parasite antigens results in recruitment of CCR2 + myeloid cells, the adoptive transfer of which ameliorates colitis. Infect. Immun. 84, 3471-3483.

Reyes, J. L., Wang, A., Fernando, M. R., Graepel, R., Leung, G., van Rooijen, N., et al. (2015). Splenic B cells from Hymenolepis diminuta-infected mice ameliorate colitis independent of T cells and via cooperation with macrophages. J. Immunol. 194, 364-378. doi: 10.4049/jimmunol.1400738

Robinson, M. W., Donnelly, S., Hutchinson, A. T., To, J., Taylor, N. L., Norton, R. S., et al. (2011). A family of helminth molecules that modulate innate cell responses via molecular mimicry of host antimicrobial peptides. PLOS Pathog. 7:e1002042. doi: 10.1371/journal.ppat.1002042

Robinson, M. W., Menon, R., Donnelly, S. M., Dalton, J. P., and Ranganathan, S. (2009). An integrated transcriptomics and proteomics analysis of the secretome of the helminth pathogen Fasciola hepatica: proteins associated with invasion and infection of the mammalian host. Mol. Cell. Proteom. 8, 1891-1907. doi: 10.1074/mcp.M900045-MCP200

Rodgers, D. T., McGrath, M. A., Pineda, M. A., Al-Riyami, L., Rzepecka, J., Lumb, F., et al. (2015). The parasitic worm product ES-62 targets myeloid differentiation factor 88-dependent effector mechanisms to suppress antinuclear antibody production and proteinuria in MRL/lpr mice. Arthritis Rheumatol. 67, 1023-1035. doi: 10.1002/art.39004

Rook, G. A. (2012). Hygiene hypothesis and autoimmune diseases. Clin. Rev. Allergy Immunol. 42, 5-15. doi: 10.1007/s12016-011-8285-8

Ruyssers, N. E., De Winter, B. Y., De Man, J. G., Loukas, A., Pearson, M. S., Weinstock, J. V., et al. (2009). Therapeutic potential of helminth soluble proteins in TNBS-induced colitis in mice. Inflamm. Bowel Dis. 15, 491-500. doi: 10.1002/ibd.20787

Sanin, D. E., and Mountford, A. P. (2015). Sm16, a major component of Schistosoma mansoni cercarial excretory/secretory products, prevents macrophage classical activation and delays antigen processing. Parasit. Vectors 8:1. doi: 10.1186/s13071-014-0608-1

Saunders, K. A., Raine, T., Cooke, A., and Lawrence, C. E. (2007). Inhibition of autoimmune type 1 diabetes by gastrointestinal helminth infection. Infect. Immun. 75, 397-407. doi: 10.1128/IAI.00664-06

Savio, L. E., and Coutinho-Silva, R. (2016). Purinergic signaling in infection and autoimmune disease. Biomed. J. 39, 304-305. doi: 10.1016/j.bj.2016. 09.002

Schnoeller, C., Rausch, S., Pillai, S., Avagyan, A., Wittig, B. M., Loddenkemper, C., et al. (2008). A helminth immunomodulator reduces allergic and inflammatory responses by induction of IL-10-producing macrophages. J. Immunol. 180, 4265-4272. doi: 10.4049/jimmunol.180.6.4265

Sewell, D., Qing, Z., Reinke, E., Elliot, D., Weinstock, J., Sandor, M., et al. (2003). Immunomodulation of experimental autoimmune encephalomyelitis by helminth ova immunization. Int. Immunol. 15, 59-69. doi: 10.1093/intimm/ dxg012

Shi, M., Wang, A., Prescott, D., Waterhouse, C. C., Zhang, S., McDougall, J. J., et al. (2011). Infection with an intestinal helminth parasite reduces Freund's complete adjuvant-induced monoarthritis in mice. Arthritis Rheum. 63, 434-444. doi: 10.1002/art.30098

Smith, J. W., and Castro, G. A. (1978). Relation of peroxidase activity in gut mucosa to inflammation. Am. J. Physiol. 234, R72-R79.

Song, X., Shen, J., Wen, H., Zhong, Z., Luo, Q., Chu, D., et al. (2011). Impact of Schistosoma japonicum infection on collagen-induced arthritis in DBA/1 mice: a murine model of human rheumatoid arthritis. PLOS ONE 6:e23453. doi: 10.1371/journal.pone.0023453

Soufli, I., Toumi, R., Rafa, H., Amri, M., Labsi, M., Khelifi, L., et al. (2015). Crude extract of hydatid laminated layer from Echinococcus granulosus cyst attenuates mucosal intestinal damage and inflammatory responses in Dextran Sulfate Sodium induced colitis in mice. J. Inflamm. (Lond) 12, 19. doi: 10.1186/s12950015-0063-6 
Spits, H., Artis, D., Colonna, M., Diefenbach, A., Di Santo, J. P., Eberl, G., et al. (2013). Innate lymphoid cells-a proposal for uniform nomenclature. Nat. Rev. Immunol. 13, 145-149. doi: 10.1038/nri3365

Srivastava, L., Tundup, S., Choi, B. S., Norberg, T., and Harn, D. (2014). Immunomodulatory glycan lacto-N-fucopentaose III requires clathrinmediated endocytosis to induce alternative activation of antigen-presenting cells. Infect. Immun. 82, 1891-1903. doi: 10.1128/IAI.01293-13

Stepek, G., Auchie, M., Tate, R., Watson, K., Russell, D. G., Devaney, E., et al. (2002). Expression of the filarial nematode phosphorylcholine-containing glycoprotein, ES62, is stage specific. Parasitology 125, 155-164. doi: 10.1017/ S0031182002001920

Stiemsma, L. T., Reynolds, L. A., Turvey, S. E., and Finlay, B. B. (2015). The hygiene hypothesis: current perspectives and future therapies. Immunotargets Ther. 4, 143-157. doi: 10.2147/ITT.S61528

Strachan, D. P. (1989). Hay fever, hygiene, and household size. BMJ 299, 1259-1260. doi: 10.1136/bmj.299.6710.1259

Su, C., Su, L., Li, Y., Long, S. R., Chang, J., Zhang, W., et al. (2017). Helminthinduced alterations of the gut microbiota exacerbate bacterial colitis. Mucosal Immunol. doi: 10.1038/mi.2017.20 [Epub ahead of print].

Summers, R. W., Elliott, D. E., Urban, J. F. Jr., Thompson, R., and Weinstock, J. V. (2005a). Trichuris suis therapy in Crohn's disease. Gut 54, 87-90. doi: 10.1136/gut.2004.041749

Summers, R. W., Elliott, D. E., Urban, J. F. Jr., Thompson, R. A., and Weinstock, J. V. (2005b). Trichuris suis therapy for active ulcerative colitis: a randomized controlled trial. Gastroenterology 128, 825-832.

Summers, R. W., Elliott, D. E., Qadir, K., Urban, J. F. Jr., Thompson, R., and Weinstock, J. V. (2003). Trichuris suis seems to be safe and possibly effective in the treatment of inflammatory bowel disease. Am. J. Gastroenterol. 98, 2034-2041. doi: 10.1111/j.1572-0241.2003.07660.x

Sun, X., Li, R., Sun, X., Zhou, Y., Wang, Y., Liu, X., et al. (2012a). Unique roles of Schistosoma japonicum protein Sj16 to induce IFN- $\gamma$ and IL-10 producing CD4+ CD25+ regulatory T cells in vitro and in vivo. Parasite Immunol. 34, 430-439. doi: 10.1111/j.1365-3024.2012.01377.x

Sun, X., Lv, Z., Peng, H., Fung, M., Yang, L., Yang, J., et al. (2012b). Effects of a recombinant schistosomal-derived anti-inflammatory molecular ( $\mathrm{rSj} 16)$ on the lipopolysaccharide (LPS)-induced activated RAW264. 7. Parasitol. Res. 110, 2429-2437. doi: 10.1007/s00436-011-2782-9

Sun, X., Liu, Y. H., Lv, Z. Y., Yang, L. L., Hu, S. M., Zheng, H. Q., et al. (2010). $\mathrm{rSj} 16$, a recombinant protein of Schistosoma japonicum-derived molecule, reduces severity of the complete Freund's adjuvant-induced adjuvant arthritis in rats' model. Parasite Immunol. 32, 739-748. doi: 10.1111/j.1365-3024.2010. 01240.x

Thomas, P. G., Carter, M. R., Atochina, O., Da'Dara, A. A., Piskorska, D., McGuire, E., et al. (2003). Maturation of dendritic cell 2 phenotype by a helminth glycan uses a Toll-like receptor 4-dependent mechanism. J. Immunol. 171, 5837-5841. doi: 10.4049/jimmunol.171.11.5837

Tundup, S., Srivastava, L., Norberg, T., Watford, W., and Harn, D. (2015). A neoglycoconjugate containing the human milk sugar LNFPIII drives antiinflammatory activation of antigen presenting cells in a CD14 dependent pathway. PLOS ONE 10:e0137495. doi: 10.1371/journal.pone.0137495

van der Kleij, D., Latz, E., Brouwers, J. F., Kruize, Y. C., Schmitz, M., KurtJones, E. A., et al. (2002). A novel host-parasite lipid cross-talk. Schistosomal lyso-phosphatidylserine activates toll-like receptor 2 and affects immune polarization. J. Biol. Chem. 277, 48122-48129. doi: 10.1074/jbc.M20694 1200 van Die, I., and Cummings, R. D. (2010). Glycan gimmickry by parasitic helminths: a strategy for modulating the host immune response? Glycobiology 20, 2-12. doi: $10.1093 /$ glycob/cwp140

Van Liempt, E., Imberty, A., Bank, C. M., Van Vliet, S. J., Van Kooyk, Y., Geijtenbeek, T. B., et al. (2004). Molecular basis of the differences in binding properties of the highly related C-type lectins DC-SIGN and L-SIGN to Lewis $\mathrm{X}$ trisaccharide and Schistosoma mansoni egg antigens. J. Biol. Chem. 279, 33161-33167. doi: 10.1074/jbc.M404988200

Versini, M., Jeandel, P. Y., Bashi, T., Bizzaro, G., Blank, M., and Shoenfeld, Y. (2015). Unraveling the hygiene hypothesis of helminthes and autoimmunity: origins, pathophysiology, and clinical applications. BMC Med. 13:81. doi: 10. 1186/s12916-015-0306-7

Walk, S. T., Blum, A. M., Ewing, S. A., Weinstock, J. V., and Young, V. B. (2010). Alteration of the murine gut microbiota during infection with the parasitic helminth Heligmosomoides polygyrus. Inflamm. Bowel Dis. 16, 1841-1849. doi: 10.1002/ibd.21299

Wang, L., Xie, H., Xu, L., Liao, Q., Wan, S., Yu, Z., et al. (2017). rSj16 Protects against DSS-induced colitis by inhibiting the PPAR- $\alpha$ signaling pathway. Theranostics 7, 3446-3460. doi: 10.7150/thno.20359

Wang, S., Xie, Y., Yang, X., Wang, X., Yan, K., Zhong, Z., et al. (2016). Therapeutic potential of recombinant cystatin from Schistosoma japonicum in TNBSinduced experimental colitis of mice. Parasit. Vectors 9:6. doi: 10.1186/s13071015-1288-1

Xia, C. M., Zhao, Y., Jiang, L., Jiang, J., and Zhang, S. C. (2011). Schistosoma japonicum ova maintains epithelial barrier function during experimental colitis. World J. Gastroenterol. 17, 4810-4816. doi: 10.3748/wjg.v17.i43.4810

Yazdanbakhsh, M., Kremsner, P. G., and van Ree, R. (2002). Allergy, parasites, and the hygiene hypothesis. Science 296, 490-494. doi: 10.1126/science.296.5567.490

Zaiss, M. M., Rapin, A., Lebon, L., Dubey, L. K., Mosconi, I., Sarter, K., et al. (2015). The intestinal microbiota contributes to the ability of helminths to modulate allergic inflammation. Immunity 43, 998-1010. doi: 10.1016/j.immuni.2015.09. 012

Zheng, X., Hu, X., Zhou, G., Lu, Z., Qiu, W., Bao, J., et al. (2008). Soluble egg antigen from Schistosoma japonicum modulates the progression of chronic progressive experimental autoimmune encephalomyelitis via Th2-shift response. J. Neuroimmunol. 194, 107-114. doi: 10.1016/j.jneuroim.2007.12.001

Zheng, X. P., Zhang, H. L., Li, H. F., Zhang, M. Z., Qiu, W., and Hu, X. Q. (2012). Neuroprotective potential beyond immunoregulation of helminth infection as a therapeutic target in multiple sclerosis. Med. Hypotheses 78, 95-97. doi: 10. 1016/j.mehy.2011.10.001

Zhu, B., Trikudanathan, S., Zozulya, A. L., Sandoval-Garcia, C., Kennedy, J. K., Atochina, O., et al. (2012). Immune modulation by Lacto-N-fucopentaose III in experimental autoimmune encephalomyelitis. Clin. Immunol. 142, 351-361. doi: 10.1016/j.clim.2011.12.006

Conflict of Interest Statement: The authors declare that the research was conducted in the absence of any commercial or financial relationships that could be construed as a potential conflict of interest.

Copyright (c) 2017 Wu, Wang, Tang and Sun. This is an open-access article distributed under the terms of the Creative Commons Attribution License (CC BY). The use, distribution or reproduction in other forums is permitted, provided the original author(s) or licensor are credited and that the original publication in this journal is cited, in accordance with accepted academic practice. No use, distribution or reproduction is permitted which does not comply with these terms. 